\title{
Uterusa sınırlı karsinosarkom ve grade 3 endometrioid endometrium kanserinin klinikopatolojik ve sağkalım analizlerinin karşılaştırılması
}

\section{Comparison of clinicopathological and survival analysis of uterus confined carcinosarcoma and grade 3 endometrioid endometrium cancer}

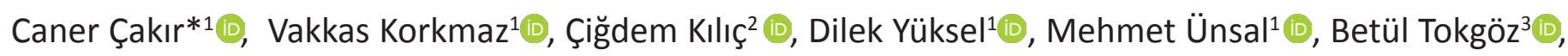

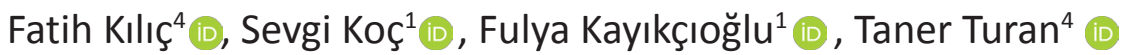

${ }^{1}$ Sağlık Bilimleri Üniversitesi, Etlik Zübeyde Hanım Kadın Hastalıkları Eğitim ve Araştırma Hastanesi, Jinekolojik Onkoloji Kliniği, Ankara, Türkiye

${ }^{2}$ Hitit Üniversitesi Tıp Fakültesi, Jinekolojik Onkoloji Kliniği, Çorum, Türkiye

${ }^{3}$ Kahramankazan Hamdi Eriş Devlet Hastanesi, Ankara, Türkiye

${ }^{4}$ Sağlık Bilimleri Üniversitesi, Ankara Şehir Hastanesi, Jinekolojik Onkoloji Kliniği, Ankara, Türkiye

\section{Öz}

Amaç: Grade 3 endometrioid endometrium kanseri (G3ECC) ve karsinosarkom (KS), ESMO-ESGO-ESRTO'un 2015'de yayınladığı konsensüsunda endometrium kanseri olguları içinde aynı risk grubunda yer alsa da, bu histolojik tiplerin biyolojik davranışları farkııdır. Bu çalışmada G3ECC olguları ile uterusa sınırlı KS vakalarının klinik sonuçlar ve sağkalım analizleri açısından karşılaştırııması amaçlandı.

Gereç ve Yöntem: Uterusa sınırlı hastalığı olan G3ECC olguları ( $n=67)$ ile uterusa sınırlı karsinosarkom (KS) olguları ( $n=54)$ klinik sonuçları ve sağkalım analizleri açısından karşılaştıııldı.

Bulgular: Uterusa sınırlı hastalık olmasına rağmen KS olan hastalarda sağkalımın belirgin kötü olduğu görüldü. Rekürrens G3ECC'de \%10,5 iken, KS'da bu oran \%27,8 olarak saptandı ( $p=0,011$ ).

Sonuç: Karsinosarkomlar erken evrede dahi G3 endometrioid endometrium kanserlerinden daha kötü prognoza sahip olabilirler.

Anahtar kelimeler: Endometrioid endometrium kanseri; grade 3; karsinosarkom; yüksek risk; endometrial kanser; rekürrens

Sorumlu Yazar*: Caner ÇAKIR, Sağlık Bilimleri Üniversitesi, Etlik Zübeyde Hanım Kadın Hastalıkları Eğitim ve Araştırma Hastanesi, Jinekolojik Onkoloji 


\section{Abstract}

Aim: Although Grade 3 endometrioid endometrial cancer (G3ECC) and carcinosarcomas (CS) are included in the same risk group among endometrial cancer cases in the consensus published by ESMO-ESGO-ESRTO in 2015, the biological behaviors of these histological types are different. In this study, we aimed to compare grade 3 endometrioid endometrial cancer cases with carcinosarcoma cases limited to the uterus in terms of clinical results and survival analysis.

Material and method: Grade 3 endometrioid endometrial cancer (G3 ECC) cases ( $n=67)$ in which the disease is limited to the uterus and uterine limited CS cases $(n=54)$ were compared in terms of clinical results and survival analysis.

Results: Despite the limited disease in the uterus, survival was significantly worse in patients with carcinosarcoma. While the recurrence rate was $10.5 \%$ in G3ECC, this rate was found as $27.8 \%$ in CS ( $p=0.011$ ).

Conclusion: Carcinosarcomas may have a worse prognosis than G3 endometrioid endometrial cancers even in the early stages.

Keywords: Endometrioid endometrium cancer; grade 3; carcinosarcoma; high risk; endometrial cancer; recurrence

\section{Giriş}

Endometrial kanser risk skorlaması ilk olarak 1987 yılında GOG-33 çalışmasında yapılmıştır. Buna göre grade 1 yüzeyel invazyonu olan hastalar düşük risk, grade $2-3$ ve $1 / 2$ myometrial invazyonu olan hastalar orta risk ve lenf nodu metastazı olan hastalar yüksek risk grubu olarak tarif edilmiştir (1). Daha sonra GOG-99 çalışmasında endometrium kanseri olgularında adjuvan tedaviyi yönlendirmek amacıyla yaş, histolojik tip, lenfovasküler stromal invazyonu (LVSI), derin myometrial invazyon ve tümörün grade'ini baz alan risk skorlama sistemi tarif edilmiştir (2). 2008 yılında retrospektif olarak yayınlanan bir diğer çalışma düşük risk grubunu yeniden tanımlamış; $(1)<2 \mathrm{~cm}$ tümörü olan, (2) $1 / 2$ 'den az myometrial invazyonu bulunan, (3) grade 1 ve 2 tümörlerin lenf nodu metastazı açısından düşük riskli olduğu ve lenfadenektominin faydalı olmadığı vurgulanarak, risk skorlamalarında tedavi yönetimi şekillendirmeye başlanmıştır (3). Daha sonra European Society for Medical Oncology (ESMO), European Society of Gynaecological Oncology (ESGO) ve European Society for Radiotherapy \& Oncology (ESRTO)'nin 2015'de yayınladığı konsensusunda endometrium kanseri olgularında düşük, orta, yüksek-orta ve yüksek risk grubu tanımlanmış olup, yüksek risk grubuna Evre 1B grade 3 (lenfovasküler stromal invazyondan bağımsız), rezidüel hastalık olmayan Evre 2-3 endometrioid ve non-endometrioid tipler (seröz ya da berrak hücreli ya da andiferansiye karsinom ya da karsinosarkom) dahil edilmiştir (4).

Ancak, ESMO-ESGO-ESRTO konsensüs raporunda belirtilmiş olan ve aynı adjuvan tedaviyi alacak olan yüksek risk grubu heterojenite göstermektedir. Örneğin, yüksek risk grubunda yer alan evre IB-II grade 3 endometrioid tümörler ve karsinosarkomlar biyolojik davranış ve sağkalım açısından farklı seyredebilen tümörlerdir. Dahası, yapılan retrospektif çalışmalarda karsinosarkomların çok daha kötü prognoza sahip oldukları bilinmektedir (5).

Yukarıdaki bilgiler ışığında, çalışmamızdaki amacımız aynı risk grubunda bulunan uterusa sınırlı evre IB-II, G3ECC ve KS'ları sağkalım ve nüks açısından karşılaştırmaktır.

\section{Materyal ve Metod}

Çalışmada Etlik Zübeyde Hanım Kadın Sağlığı ve Hastalıkları Eğitim ve Araştırma Hastanesi'nde 1993-2019 yılları arasında endometrium kanseri nedeniyle opere edilen 2450 hasta retrospektif olarak tarandı. Uterusa sınırlı 67 tane Evre IB-2 G3ECC olgusu (Grup 1) ve 54 KS olgusu (Grup 2) çalışmaya dahil edildi (Şekil 1). Çalışmadan dışlama kriterlerimiz; (1) düşük risk (Evre I endometrioid G1-2, \%50> myometrial invazyon, LVSI (lenfovasküler stromal invazyon) negatif, orta risk (Evre I endometrioid G1-2, \%50<myometrial invazyon, LVSI negatif) ve yüksek-orta risk (Evre I endometrioid, grade 3, <50\% myometrial invazyon, LVSI'den bağımsız, Evre I endometrioid, grade $1-2$, LVSI kesin pozitif, derin myometrial invazyondan bağımsız) olguları, (2) ekstrauterin hastalığı olan olgular, (3) senkronize tümörü olanlar, (4) sekonder malignite gelişmiş hastalar, (5) cerrahi sonrası ilk ay içerisinde ölenler, (6) sekonder sitoredüksiyon yapılan hastalar (7) hastanemiz dışında opere olanlar (8) inkomplet verisi olanlar dışlanmıştır (Şekil 1). 


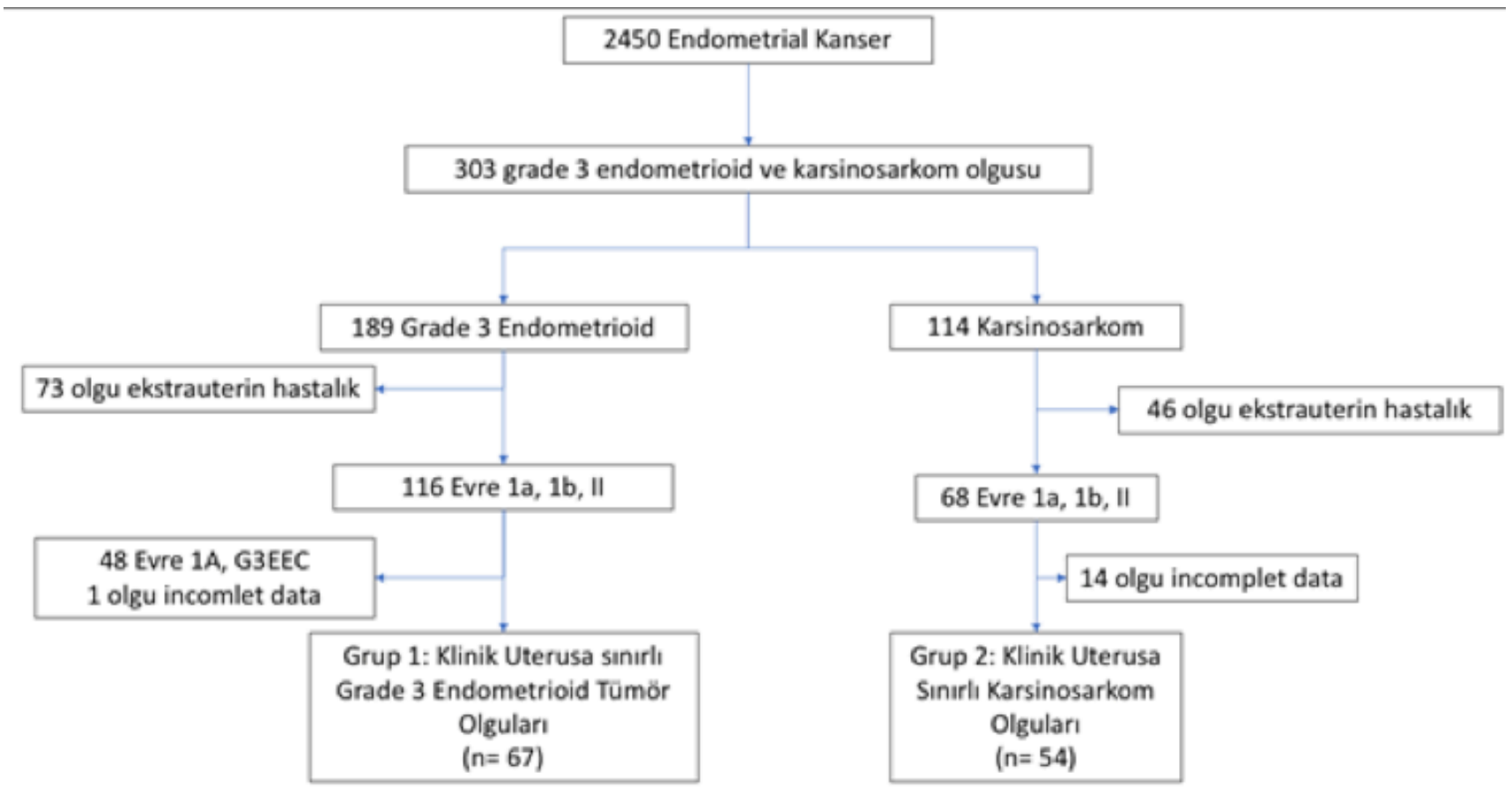

Şekil 1. Çalışma Akış Şeması

Standart cerrahi yaklaşım batın eksplorasyonu sonrası, en az total abdominal histerektomi, bilateral salpingo-ooforektomi, omentektal biyopsi, peritoneal sitoloji ve retroperitoneal lenfadenektomi şeklindeydi.

Hastaların klinik verileri ve takip sonuçları patoloji raporlarından, tıbbi kayıtlardan, ameliyat notlarından ve jinekolojik onkoloji kliniği elektronik veri tabanı sisteminden elde edildi. Yaş, CA-125, çıkarılan pelvik lenf nodu sayısı ve paraaortik lenf nodu sayısı, rekürrens zamanı, takip süresi ile ilgili veri toplandı. Evreleme için 2009 Uluslararası Jinekoloji ve Obstetri Federasyonu (FIGO) kriterleri kullanıldı. 2014'ten önce tedavi edilenlerin evreleri cerrahi ve patoloji verileri kullanılarak FIGO 2009 sistemine göre düzenlendi (6). Hastaların tümü adjuvant tedavi olarak 6 kür Karboplatin+Paklitaksel ve radyoterapi almışlardı.

Ameliyat sonrası takipler, operasyon sonrası ilk 2 yıl 3 ayda bir, sonraki 3 yıl 6 ayda bir, ardından gelen 5 yıl yılda 1 defa olacak şekilde gerçekleştirildi. Her takipte jinekolojik muayene, tüm abdominal ultrasonografi, CA-125 düzeylerinin ölçümü rutin olarak yapıldı. İleri radyolojik görüntüleme (Pozitron Emisyon Tomografi veya Bilgisayarlı Tomografi) sadece rekürrens şüphesi olduğunda kullanıldı. Genel sağkalım (OS), primer cerrahi ile ölüm veya son temas arasında geçen süre olarak tanımlandı.

Hastalıksız sağkalım (DFS), klinik muayene ve / veya radyolojik görüntüleme ile primer cerrahiden belgelenmiş rekürren hastalığa kadar geçen süre olarak tanımlandı.
Veri yönetimi ve istatistiksel analiz için SPSS 17.0 (SPSS Inc., Chicago, IL) kullanılmıştır. Verilerin dağılımı Kolmogrov Smirnov normallik testi ile değerlendirildi.

Preoperatif CA-125 düzeyi, pelvik lenf nodu sayısı (LNS) ve para-aortik LN sayıları ise normal dağılmadığı için median (minimum-maksimum) ile ifade edildi. Kategorik değişkenler ise sayı / yüzde olarak ifade edildi. Parametrik dağılım gösteren verilerin karşılaştırılması için Student t test (Independent t test), parametrik olmayan verileri karşılaştırmak için Mann Whitney-U testi ve kategorik değişkenler için ki-kare testi kullanıldı. Sağkalım sonuçlarının değerlendirilmesinde Kaplan-Meier yöntemi, sağkalım dağılımlarını karşılaştırmak için log rank testi kullanıldı. Lokal etik komiteden çalışmanın yapılabileceğine dair izin alınmıştır (90057706-799).

\section{Bulgular}

Çalışmada patolojik olarak uterusa sınırlı 67 G3EEC ve 54 KS olgusu olmak üzere toplam 121 hasta analiz edildi. Dahil edilen hastaların median yaşı 62 (39-79) yıl, median serum CA-125 düzeyi 15 IU/ $\mathrm{mL}$ (1-242), median çıkarılan pelvik lenf nodu sayısı 36 (18-70) ve median çıkarılan para-aortik lenf nodu sayısı 16 (6-46) idi.

\subsection{Grupların Karşılaştırılması}

İki grubun karşılaştırılmasında yaş, preoperatif serum CA-125 düzeyi, çıkarılan pelvik lenf nodu sayısı ve çıkarılan para-aortik lenf nodu sayısı açısından fark yoktu ( $p>0,05)$ (Tablo 1). 


\begin{tabular}{|c|c|c|c|}
\hline & $\begin{array}{l}\text { Grup } 1 \text { (G3EEC) } \\
\qquad \mathrm{n}=67\end{array}$ & $\begin{array}{l}\text { Grup } 2 \text { (CS) } \\
\quad \mathrm{n}=54\end{array}$ & $\mathrm{p}$ \\
\hline Yaş $^{1}$ & $59,8 \pm 8,3$ & $62,2 \pm 9,5$ & 0,208 \\
\hline Preop CA-125² & $13(1-242)$ & $16(2-325)$ & 0,263 \\
\hline Pelvik LNs ${ }^{2}$ & $37(19-82)$ & $36(5-65)$ & 0,051 \\
\hline Paraaortik LNs ${ }^{2}$ & $16(3-47)$ & $18(2-49)$ & 0,933 \\
\hline Rekürrens $^{3}$ & $10,5(7 / 67)$ & $27,8(15 / 54)$ & 0,011 \\
\hline Ölüm & $2,9(2 / 67)$ & $16,7(9 / 54)$ & 0,008 \\
\hline Takip zamanı² & $48(2-240)$ & $25(2-192)$ & 0,04 \\
\hline \multicolumn{4}{|c|}{$\begin{array}{l}{ }^{1} \text { Ortalama } \pm \text { SD; }{ }^{2} \text { Median (minimum-maksimum); }{ }^{3} \% \text {, sayı } \\
\text { SD:Standart Deviasyon }\end{array}$} \\
\hline
\end{tabular}

Grade 3EEC olgularının \%10,5 (7/67)'unda rekürrens saptanırken, KS olgularının \%27,8'inde (15/54) rekürrens saptandı $(p=0,011)$. Rekürrensler G3ECC'de 3 hastada akciğer, 1 hastada üretra ve 3 hastada vajen kafında idi. KS'da ise 6 hastada akciğerde, 2 hastada paraaortik lenf nodlarında, 2 hastada pelvik peritonda, 2 hastada karaciğerde, 1 hastada abdominal peritonda, 1 hastada batın ön duvarı subkutanöz dokuda ve 1 hastada vajinal kafta idi.

Takip süresi içerisinde G3EEC'da 2 hasta eksitus olurken, KS'da 9 hasta eksitus olmuştu $(p=0,008)$.

\subsection{Sağ kalım analizi}

ikigrup sağkalım açısından karşılaştıııldığında, Grup 1'de (G3EEC) 5 yıllık ortalama sağkalım \%95,3 iken, KS grubunda $\% 67,4$ idi ( $p$ $=0.003$ ) (Şekil 2). Beş yıllık DFS ise Grup 1'de (G3EEC) \%83 iken, Grup 2 (KS) olgularında \%47,6 idi ( $p=0,002)$ (Şekil 3).

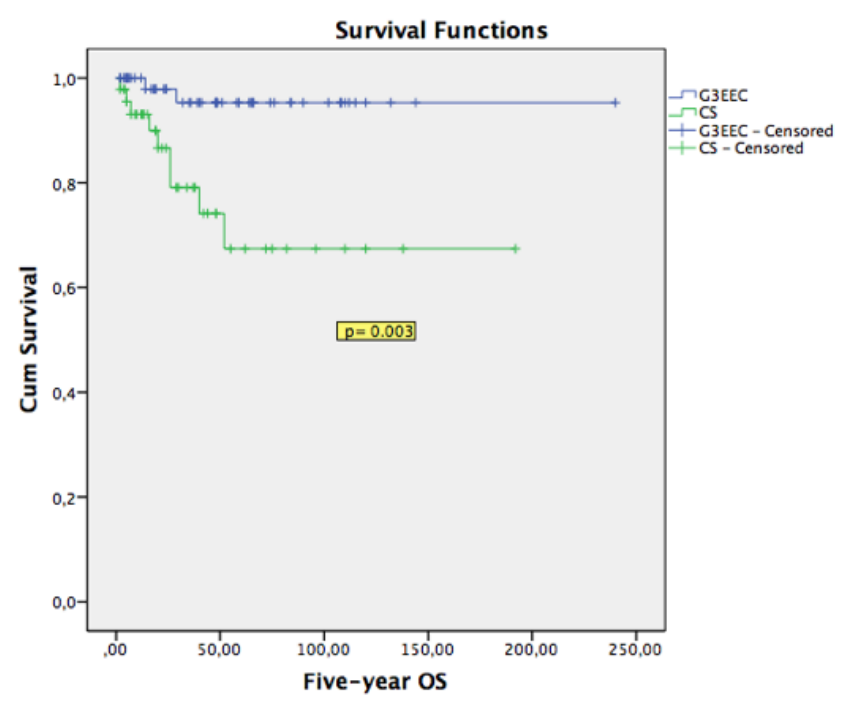

Şekil 2. Beş yıllık OS oranlarının karşılaştırılması

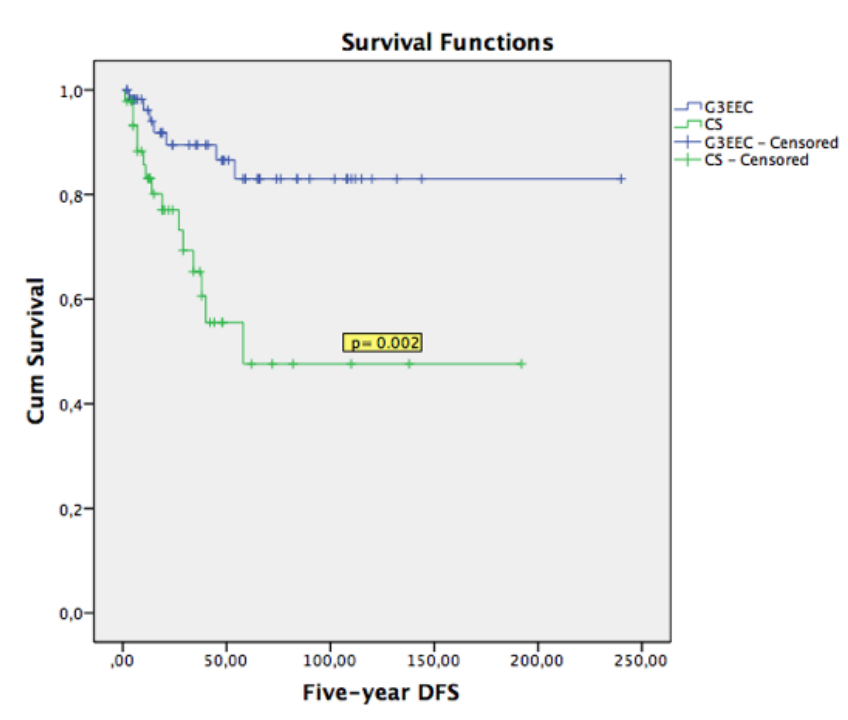

Şekil 3. Beş yıllık DFS oranları açısından karşılaştırma

\section{Tartışma}

Uterin KS ve G3EEC'ler, endometrial kansere bağlı ölümlerin önemli bir bölümünün sebebidir. Bu iki tümör cerrahi ve postoperatif adjuvan tedavi olarak da benzer şekilde yönetilmektedir. Ancak yapılan retrospektif çalışmalarda karsinosarkomların daha kötü prognoza sahip oldukları belirtilmiştir $(4,5)$. Bu nedenle bu çalışmada bu iki tümörün erken evredeki subgruplarını belirleyerek klinik özellikleri ve sağkalım sonuçlarını karşılaştırdık ve çalışmanın sonunda karsinosarkomların erken evrelerde bile daha kötü sonuçlar ile ilişkili olduğunu saptadık.

Bansal ve ark.larının 1998-2004 yılları arasındaki tanı alan hastaların retrospektif olarak yayınladıkları G3ECC ve KS'lerin tümör davranışlarına baktıkları çalışmalarında 8,986 hasta bulunmaktadır. Bunların \%56'sı G3ECC ve \%44 ü KS'dir (7). Uterin karsinosarkomlar G3ECC'ye göre daha yaşlı hastalarda görülmektedir $(P<0,001)$.Benzer şekilde çalışmamızda da KS'lerin yaşortalaması daha yüksek tespit edildi. KS'lerin G3ECC vakalarına göre daha ileri evrede yakalandıklarını belirten bu çaıışmada kötü prognoza ileri evrenin de katkısı bulunduğunu vurgulamıştır. Buna rağmen erken evrede özellikle uterusa sınırı hastalıkta bakılan 5 yıllık sağkalım analizinde Evre 1B G3ECC'e göre KS'da sağkalım daha kötü izlenmiştir (\%83 \& \%54, p<0,001). Evre 2 G3ECC ile KS karşılaştıııldığında 5 yıllık sağkalım (\%60 \& \%35, p<0,001) yine KS'da daha kötü izlenmiştir. Bu bulgular çalışmamızla benzer olup, uterusa sınırlı hastalık olan erken evrede bile KS'ların daha kötü prognoza sahip olduklarını söyleyebiliriz. Zhang ve ark. ları KS ( $n=44)$, G3ECC $(n=118)$, uterus seröz karsinomu ( $n=$ 118) ve uterus berrak hücreli adenokarsinomunun $(n=78)$ klinikopatolojik özelliklerini karşılaştırmışlar, KS'ların anlamlı 
olarak daha kötü sonuçları olduğunu göstermişlerdir. Ayrıca KS hastalarında P53 pozitiflik oranının G3EEC hastalarına göre daha yüksek olduğunu bulmuşlardır (8).

Prueksaritanond ve ark.larının FIGO evre I-IV endometrial kanseri olan hastalarda yapılan bir başka retrospektif derlemesinde 45 uterin papiller seröz karsinom, 58 şeffaf hücreli karsinom, 58 G3ECC ve 30 KS olgusunu analiz etmişlerdir. Çalışmanın sonunda, KS olgularında 2 yıllık progresyonsuz sağkalım ve 2 yıllık genel sağkalımın daha kötü olduğu saptanmıştır (9).

Bu konuda yapılmış önemli diğer bir çalışma ise Zhu ve ark. ları tarafından 2006-2013 yılları arasında yapılan retrospektif çalışmadır. Bu çalışmada 60 tane uterin KS, 115 tane G3ECC olgusu karşılaştırılmıştır. Çalışmanın sonunda, uterin $\mathrm{KS}^{\prime}$ ların daha fazla asit oluşumu ( $55 \%$ vs. 15,7\%, p<0,001), daha fazla adneksiyel tutulum $(20,0 \%$ vs. $8,7 \%, p=0,048)$ ve artmış tümör

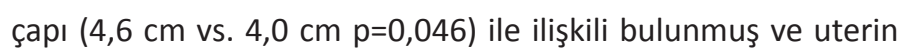
KS ile grade 3 endometrioid tümörlerin farklı klinikopatolojik özellikte oldukları, ayrı risk gruplarında değerlendirilmeleri gerektiği belirtilmiştir. Bizim çalışmamız bu çalışma ile sonuçları açısından paralellik göstermesi ile birlikte, bu çalışmada tüm evredeki tümörler ele alınmıştır. Çalışma popülasyonun ayrıntılı analizine baktığımızda KS'ların sadece 37 tanesi erken evrede (I ve II) iken G3EEC'ların sadece 68 tanesi erken evredeki (I ve II) tümörleri oluşturmaktadır (10). Dahası farklı evrelerin dahil edilmesi ile gruplarda oluşan heterojenite çalışma sonuçlarını, çalışmanın literatüre katkısını da sınırlandırmaktadır. Bu nedenlerle bizim çalışmamızın uterusa sınırlı tümörlerle sınırlı olması, bu spesifik grupta rölatif yüksek hasta sayımız yapılmış olan bu çalışmaya üstünlüklerimizdir. Çalışmanın doğası gereği retrospektif olması temel limitasyondur.

Sonuç olarak uterusa sınırlı G3ECC ile KS ortalama sağkalım ve DFS açısından farklı olan tümörler olup, erken evrede bile KS'lar daha kötü prognoza sahip olabilirler. Bu nedenle bu iki tümör grubunun yüksek risk grubunda beraber bulunmasından ziyade, yüksek risk grubunda da kendi içerisinde farklı iki subgrup olarak bulunmasının endometrium kanseri risk skorlamalarının prognozu yansıtması ve adjuvan tedaviyi yönlendirmeleri açısından daha doğru olacağını düşünmekteyiz.

\section{Çıkar Çatışması}

Bu yazı tamamı ile bilimsel amaçla yazılmış olup, yazarların bu yazı ile ilgili herhangi bir çıkar çatışması bulunmamaktadır.

\section{Kaynaklar}

1. Creasman WT, Morrow CP, Bundy BN, Homesley HD, Graham JE, Heller PB. Surgical pathologic spread patterns of endometrial cancer. A Gynecologic Oncology Group Study. Cancer 1987; 60(8 Suppl):2035-2041.

2. Creutzberg CL. GOG-99: ending the controversy regarding pelvic radiotherapy for endometrial carcinoma? Gynecol Oncol 2004; 92:740-743.

3. Mariani A, Dowdy SC, Cliby WA ve ark. Prospective assessment of lymphatic dissemination in endometrial cancer: a paradigm shift in surgical staging. Gynecol Oncol 2008; 109:11-18.

4. Colombo N, Creutzberg C, Amant F ve ark. ESMO-ESGO-ESTRO Endometrial Consensus Conference Working Group. ESMO-ESGOESTRO consensus conference on endometrial cancer: Diagnosis, treatment and follow-up. Radiother Oncol 2015; 117:559-581.

5. Vaidya AP, Horowitz NS, Oliva E, Halpern EF, Duska LR. Uterine malignant mixed mullerian tumors should not be included in studies of endometrial carcinoma. Gynecol Oncol 2006; 103:684-687.

6. Creasman W. Revised FIGO staging for carcinoma of the endometrium. Int J Gynaecol Obstet 2009; 105:109.

7. Bansal N, Herzog TJ, Seshan VE, et al. Uterine carcinosarcomas and grade 3 endometrioid cancers: evidence for distinct tumor behavior. Obstet Gynecol 2008; 112:64-70.

8. Zhang $\mathrm{C}, \mathrm{Hu} \mathrm{W}$, Jia $\mathrm{N}$ et al. Uterine carcinosarcoma and high-risk endometrial carcinomas: a clinicopathological comparison. Int J Gynecol Cancer 201; 25:629-636.

9. Prueksaritanond N, Chantape W. Comparative Survival Outcomes of UterinePapillary Serous Carcinoma, Clear Cell Carcinoma, Grade 3 EndometrioidAdenocarcinoma, and Carcinosarcoma of Endometrial Cancer in Rajavithi Hospital. J Med Assoc Thai 2016; 99:S75-83.

10. Zhu J, Wen H, Bi R, Wu X. Clinicopathological characteristics, treatment and outcomes in uterine carcinosarcoma and grade 3 endometrial cancer patients: a comparative study. J Gynecol Oncol 2016; 27:e18. 